\title{
Theoretical and Experimental Vibration Analyses of the Steering Wheel of a Heavy Commercial Vehicle
}

\author{
Adil Yucel and Begum Derebay \\ Department of Mechanical Engineering, Istanbul Technical University, Gumussuyu, Beyoglu, Istanbul, Turkey. \\ E-mail: adil.yucel@itu.edu.tr.
}

\begin{abstract}
(Received 1 August 2020; accepted 24 February 2021)
In this study, the components of a particular heavy commercial truck that affect the steering wheel vibration are identified and the most common sources of this vibration are examined. Then, modal analyses and impact hammer tests are implemented to determine the root causes of the vibration. Finally, finite element modeling is applied, and all the results of the analyses are compared to present design improvement recommendations for the reduction in steering wheel vibration, which can be applicable in new projects.
\end{abstract}

\section{INTRODUCTION}

Steering wheel vibration is one of the greatest contributing factors to noise, vibration, and harshness (NVH) problems in automotive engineering since it directly affects the driver's comfort. This vibration has been a serious problem, especially for long distance drivers such as heavy commercial vehicle drivers due to their long exposure periods. The main objectives of this study are to develop a good understanding of potential sources of steering wheel vibration, obtain both the modal frequencies and parameters of the steering wheel of a particular heavy commercial vehicle model program code named HXXX (the XXX placeholder is used to preserve the privacy of the product) by use of finite element vibration analysis, the modal impact hammer test, and correlation of steering wheel model. The purpose of this study is also to investigate the root causes of steering wheel vibration in the heavy commercial vehicle and to validate computer-aided engineering (CAE) models of the steering wheel and trimmed body with the results of experimental modal analyses performed on the steering wheel and column. Once the correlation between the finite element analysis (FEA) and test results is established, several design change iterations and their effects on the dynamic behavior of the steering system can be observed without performing further tests.

Steering wheel vibration is affected by various internal and external vibrational sources. The internal sources are the rotational irregularity of the engine which is caused by both the stochastic combustion forces and the dynamic unbalance of components such as the translating pistons. The external sources include the road surface irregularities and the aerodynamic forces. For both the internal and external sources the vibration which reaches the driver is moderated by the dynamic response of the automobile chassis components. There are many factors that may cause the vibration in idle including the vibrational excitation sources, such as the engine and engine mounts; the transmission channels, such as the body structure, suspension, and the steering wheel itself. Thus, identifying the source of the vibration becomes a very complex problem.
Therefore, a procedure had been applied to identify this vibration phenomenon and to search alternatives to decrease or eliminate it. To identify the problem, a series of tests had been performed.

During the development phase of the truck which is under consideration, numerous tests and analyses had been performed to determine the main cause of the vibration. In consequence of these studies, improvement was achieved in vibration levels, but it was not eliminated to a negligible level. In this paper, detailed analyses were carried out to see the characteristics of the source and response system and CAE model correlation study as one of the most important factors as an initial step for design improvement has been carried out.

There have been several detailed studies regarding the sources of methods followed to detect the causes of and ways to improve steering wheel vibration. Analysis and experiments have been conducted to understand the main causes of steering wheel vibration and possible solutions that could help minimize it. Several improvement methods have been implemented as well.

Szczotka $^{1}$ developed a simplified planar model of a passenger car steering system and applied nonlinear optimization methods to select parameters to minimize steering wheel vibrations.

Kim et al. $^{2}$ conducted a study on shudder vibration of a hydraulic power steering system during parking maneuvers by numerical and experimental methods. A CAE model for steering wheel vibration analysis was developed and compared with measured data.

According to Mangun, ${ }^{3}$ excessive torsional vibrations in the steering system are mainly caused by a nonuniform tire/wheel assembly producing periodic force variations. A parameter sensitivity study was performed and showed that appropriate tuning of the inertial and frictional properties of the steering system and suspension parameters substantially decreased the transmission of these vibrations.

Sugiyama et al. ${ }^{4}$ presented a new control strategy for electric power steering that they developed to reduce the steering 
vibration associated with disturbance from the road wheels.

Zhang et al. ${ }^{5}$ investigated steering wheel vibration caused by brake judder. Tests were conducted under controlled braking conditions, and modeling and simulations were carried out to both reproduce and explain the results of vehicle road tests and brake dynamometer tests.

Matsunaga et al. ${ }^{6}$ constructed a mathematical model for a hydraulic power steering system and performed numerical analysis for self-excited vibration caused by rapid steering in the system.

Wang et al. ${ }^{7}$ used vibration tests and modal analysis methods to determine the cause of steering wheel idle shaking. The steering wheel's operating modal was close to the engine's second-order excitation frequency, which caused the steering wheel to shake at idle.

Demers ${ }^{8}$ developed a methodology for the diagnosis of steering wheel vibrations and investigated the possible sources of these vibrations and how various steering system parameters might affect them.

Kim et al. ${ }^{9,10}$ discussed the vibration characteristics of the steering wheels in front-drive small-sized passenger cars. Measurements of the vertical and lateral accelerations at the steering wheel were taken from a small-sized passenger car on a typical road. The effects of engine vibration, road excitation and structural system characteristics were identified by experimental and analytical methods.

Botti et al. ${ }^{11}$ developed an approach for optimizing the instabilities of the power steering systems of passenger cars at an early design stage by using specialized computer simulations.

Su et al. ${ }^{12}$ investigated vibration problems in a midsized passenger car under idle conditions by testing and analysis. The root of the severe vibration of the steering wheel under idle conditions was that the steering wheel first-order natural frequency was too close to the engine's second-order frequency.

Slave et al. ${ }^{13}$ used CAE models that were validated by experimental measurements to identify the modes of vibration in the cab of a truck and vehicles that have a significant influence on the steering column response.

Chen et al. ${ }^{14}$ created a model of a steering system based on the finite element method (FEM) to understand the vibration characteristics of the system. Twenty step modes of the system were calculated and analyzed by modal analysis.

Guo et al. ${ }^{15}$ applied the three-dimensional FEM to a steering wheel and conducted finite element (FE) static and dynamic analyses to validate the dynamic characteristics and strength of the associated steering system.

Gao and Wang ${ }^{16}$ built a three-dimensional model of an automobile electric power steering system. The structure design and dynamic characteristic optimization of the model were researched, and based on natural frequency analysis, several design improvement schemes were proposed to avoid overlap of the system natural frequency and the engine excitation frequencies at idling speed.

Bianchini ${ }^{17}$ described an approach to implement a costeffective active vibration control system applied to a steering column. He designed an active control system to eliminate the transmission of vibrations from the idling engine to the steering wheel.
Landreau and Gillet $^{18}$ analyzed steering wheel vibration through testing and numerical modal analysis in their study. A dynamic mode was identified to be responsible for the sensitivity of the vehicle.

Zhang and Dong ${ }^{19}$ built a steering mechanism simulation model and performed dynamic simulation analysis using the multibody system dynamic method. A flexible tie-rod model and a rigid-flexible coupling steering mechanism model were built, and the corresponding natural modes were obtained by ANSYS.

Othman ${ }^{20}$ noted that the major cause of steering wheel vibration is engine vibration but that the vibration level is different for every steering wheel model depending on its shape, design, weight, material and size.

Shim and $\operatorname{Shin}^{21}$ presented a design process for a highstiffness steering system using lightweight magnesium alloy, and the results provided an improvement of approximately $10 \mathrm{~dB}$.

Kim and $\mathrm{Choi}^{22}$ presented an optimal design process for a steering column system and the supporting system. Case studies regarding resonance isolation were summarized, in which vibration modes were separated among systems by applying a mode map at the initial stage of the design process.

Abreu and Moura ${ }^{23}$ used techniques such as mechanical vibration analysis, operational modal analysis, and the operational deflection shape to identify the root cause of increased levels of vibration at idle speed in the prototype of a popular vehicle.

Britto et al. ${ }^{24}$ discussed the methodology of steering assembly development to improve the NVH performance of commercial vehicles. This study dealt with steering wheel target setting and cascading to the system, subsystem and component level targets and achieving these targets by a collaborative test-CAE approach.

Fujiwara and Nakayasu ${ }^{25}$ analyzed vibration phenomena in the steering system of a vehicle when the front wheels had certain amounts of unbalance. The influences acting on the rotational vibration at the steering wheel end were determined by varying each factor in the vibration system by actual running tests.

Sugita and Asai $^{26}$ described an experimental method for the reduction in steering wheel vibration occurring at highspeed cruising and/or engine idling. Reduction was found to be achieved by increasing the resonant frequency of the steering system, including the steering wheel, steering column, and support members.

Kim and $\mathrm{Choi}^{22}$ studied several steering wheel vibration problems, and detailed analysis was carried out to determine the characteristics of the source and response systems. A dualmode steering wheel dynamic damper was developed to control shake and shimmy problems.

Shi et al. ${ }^{27}$ investigated the cause of steering wheel idle shaking through vibration tests and modal analysis methods. The steering system's operational modal was close to the 2ndorder excitation frequency of the engine, and the steering wheel resonated.

Xie et al. ${ }^{28}$ proposed test and simulation integrated transfer path analyses and optimization methods to decrease steer- 
ing wheel vibration in idle mode. First, the contributors to the vibration were studied, including the vibrational excitation sources, transmission channels, and steering wheel itself. Then, a series of improvements were carried out, including lowering the engine idle speed when the $\mathrm{AC}$ is on, tuning the engine mounts to decrease the engine vibration, and improving the body structure and the support brackets of the steering column.

Giacomin et al. ${ }^{29}$ investigated the human perception of rotational hand-arm vibration by means of a test rig consisting of a rigid frame, electrodynamic shaker unit, rigid steering wheel, shaft assembly, bearings and automobile seat.

According to Ereke, ${ }^{30}$ in the process of developing less sensitive axle and steering wheel systems, subjective assessment of the driver's perception of the vibration should be a concern in addition to endeavors to reduce the acceleration values.

$\mathrm{Jeon}^{31}$ performed experiments to quantify the human subjective response to automotive steering wheel vibration and used the findings to define a test method for automotive steering wheel hand-arm vibration.

$\mathrm{He}$ et al..$^{32}$ studied the intrinsic characteristics and vibration isolation performances of the powertrain suspension system aiming at solving the problem of a certain type of commercial vehicle's steering wheel with strong idle jitter at the idle state. As the conclusion, the effectiveness and feasibility of the optimization algorithm to solve the problem of the vehicle's steering wheel jitter at idle states were verified through a test using multiple acceleration sensors, which has practical values in the engineering field.

He et al. ${ }^{33}$ also conducted a high-speed vibration frequency sweep experiment on an unladen commercial vehicle to determine the resonance frequency of the vehicle components. A vibration waterfall plot of the collected vibration data revealed that the cause of the vibration was frequency coupling resonance between the steering wheel vibration frequency and the second-order rotation frequency of the tire. Thus, a combined optimization of the structure of the rigid bearing parts of the steering fixed support and the steering column structure was proposed. A combination of finite-element analysis and modal testing method was undertaken to verify the effectiveness of the proposed combined structural improvement; the results demonstrated the consistency of the combined methods and showed that the natural frequency of the improved steering structures, together with the vibration amplitude, had changed. This study demonstrated the feasibility of the combined modal testing and finite-element analysis method, provided more information on the vibration transfer characteristics related to the vehicle subsystems, and provided a reference for the structural design of steering systems with reduced vibration.

Peng $^{34}$ adopted GA-BPNN algorithm to optimize the top two order frequencies of steering systems. Firstly, the study established the multi-body dynamics model of the steering system and obtained the random spectrum of 4 wheels through mathematical model. Then, vibration accelerations of the steering wheel at different positions were extracted through the multi-body dynamics model of steering system. The finite element model of steering system was established to compute the vibration acceleration, and it was compared with the experi- mental result. Finally, GA-BPNN algorithm was proposed to optimize the structural thickness of key parts on the steering system, and the optimized result was then compared with that of BPNN and PSO-BPNN.

He et al. ${ }^{35}$ presented a multi-point iterative analysis method (MIAM) in their study. Considering the structural characteristics of the modal deformation of the car body, the installation orientation of the measuring point is further adjusted according to the area formed by modal deformation nodes, and a simplified vibration transfer path is presented.

Sangeeta et al. ${ }^{36}$ aimed to perform design optimization of a steering rod to nullify its function-ability issues related with stresses, deformation, vibrations, etc. This suggests an alternative way for nullifying problems and to minimize the cost by saving the material.

Pattathil et al. ${ }^{37}$ introduced dynamic steering wobble analysis methodology either using vehicle speed at Discrete (individual speeds) or by the Sweep (low to high speed) method to investigate steering wobble in the virtual environment using the full vehicle MBD model. It is also suggested that prior to wobble analysis, vehicle level modal analysis should be executed to locate and separate different coupling modes and its shapes in working resonance bandwidth of system.

Sendur et al. ${ }^{38}$ examined the root cause and lays-out the improvement steps of excessive steering wheel vibration on a heavy truck. The transmissibility of powertrain idle vibration to cabin is investigated with respect to powertrain roll mode and modal alignment of the steering system is considered.

Fridman et al..$^{39}$ proposed a method for automated synchronization of vehicle sensors useful for the study of multi-modal driver behavior and for the design of advanced driver assistance systems. Cross-correlation of accelerometer, telemetry, audio, and dense optical flow from three video sensors was used to achieve an average synchronization error of 13 milliseconds. The insight underlying the effectiveness of the proposed approach is that the described sensors capture overlapping aspects of vehicle vibrations and vehicle steering allowing the cross-correlation function to serve to compute the delay shift in each sensor.

Prashanth et al. ${ }^{40}$ aimed to study the vibration of the steering assembly of a commercial vehicle and to establish a simplified mathematical model to represent the harmonics involved in the vibrating system. The work attempted to study the correlation of steering assembly vibrations between an existing commercial vehicle and optimized steering assembly. The study also tried to present a basic mathematical model to which will help in understanding the various design and material conditions/constraints involved in designing of a steering wheel assembly and establishes a worst-case criteria for developing the mathematical model.

Reddy ${ }^{41}$ conducted a guidance vibration learn on quite a lot of tractor models (40-50 kW variety) and one tractor was recognized for growth. Upon targeted analysis on that designated tractor, it used to be found that the resonance of steerage process with engine excitation is the foundation purpose for excessive vibration. In the study, two ideas had been selected, specifically radial damper and axial damper ideas for additional processing. These new design standards had been 
modeled as a 2 degree of freedom (2-DOF) procedure with aid movement from engine vibration as enter. Expressions have been derived for vibration transmissibility from engine to guidance wheel and coded in MATLAB. A simulation used to be carried out in ADAMS program. It was once observed that steerage vibration anticipated by the mathematical model matched well with the measured values.

Shelke and Dhale ${ }^{42}$ managed investigation of vibration related issues in the controlling wheel of a tractor. A steering vibration study conducted on power trac 439 DS. Tuned mass damper idea is utilized for vibration decrease. Various damping materials are tried for vibration lessening and analysis is done in MATLAB Simulink with two degree of freedom model with base excitation.

Velmurgan et al. ${ }^{43}$ aimed to find out the vibrational analysis for different car steering for different road profiles. Another one of their aims was to both collect the vibrational values and to know the vibration of the steering in different road conditions.

Ye et al. ${ }^{44}$ proposed a systematic analysis methodology to reduce the low-frequency vibration of steering wheel using classical transfer path analysis (CTPA) in their study. The theoretical basics of TPA using dynamic stiffness approach and inverse matrix approach were briefly introduced, and then the experimental apparatus and analysis procedures in performing the TPA were introduced. The static forces in the rubber mounts of the powertrain system were calculated, the dynamic stiffness of the rubber mounts were estimated, and the operational forces were determined. The contributions of different transfer paths to the vibration of steering wheel were analyzed and compared, and the predominant causes are identified. The results show that the vibration of steering wheel along the $\mathrm{X}$ direction is protruded at the engine ignition frequency, and the vibration of the exhaust system along the $\mathrm{X}$ direction contributes most to the vibration because of large frequency response function.

In general, a steering system is designed to enable the driver to control the path traveled by a vehicle. The steering system must give the operator some form of feedback that allows $\mathrm{him} / \mathrm{her}$ to feel an approximation of the load condition that the vehicle tires are experiencing. This feedback is very important for allowing the driver to easily control the direction of travel. The CAE model of the vehicle that was investigated is shown in Fig. 1.

The main components of the steering system of a truck are steering wheel, steering column, steering gear, and steering linkages including Pitman arm, drag link that move the steering tires. The steering wheel is the instrument used by the driver to control the directional tracking of the vehicle. Therefore, steering wheel is the primary input to the steering system. The steering wheel used on a truck supported by spokes extend from the wheel hub, which turns on a bushing or bearing at the top of the steering column. The steering column connects the steering wheel to the steering gear. The main function of steering column is to transfer the rotational moment from the steering wheel to the steering gears. The steering column is usually sectional (retractable) and designed to collapse in the event of a collision. The typical vehicle requires about three complete

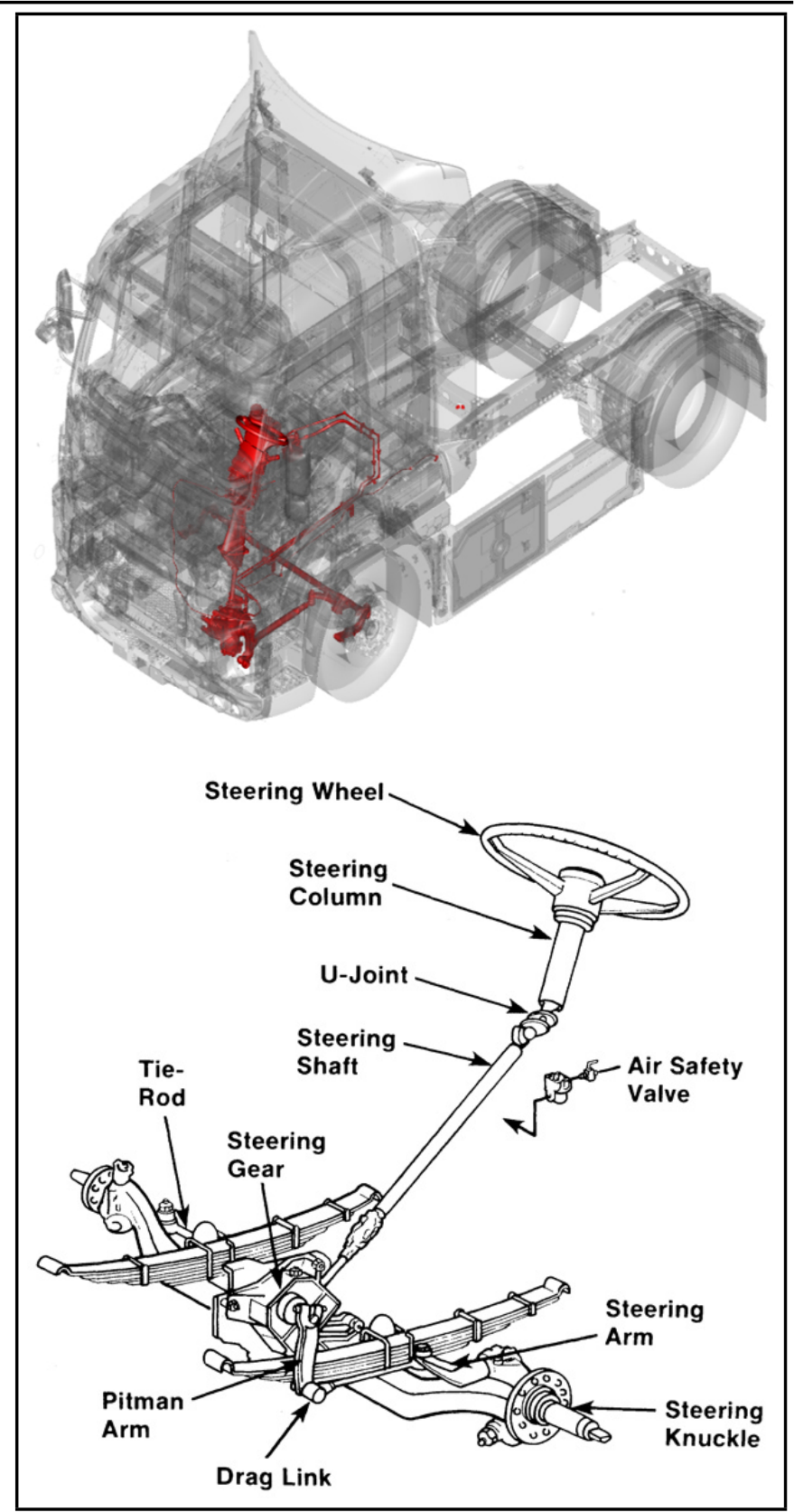

Figure 1. HXXX CAE model.

revolutions of the steering wheel to rotate front wheels from full left to full right. The steering wheel is bolted to splined steering shaft in the steering column. The steering column consists of the jacket tube called as steering housing fixed to the body and steering shaft (also called steering tube). The major components of the steering column assembly are tube, bearing assemblies, a steering column shaft and wiring and the contact assemblies for the electric horn. The steering column assembly is mounted to the dash steering column bracket by support brackets located under the cover housing. Coupled to the steering column upper shaft by a pair of yokes and the U-joint assembly is the lower shaft assembly. The U-joint permits some angular deviation between the upper and lower column shafts. The lower column assembly connects to the steering gear. A Pitman arm is a steel lever, splined to the sector (output) shaft of the steering gear. The end of the Pitman arm moves through an arc with the sector shaft center forming its center. The Pit- 
man arm functions to change the rotary motion of the steering gear sector shaft into linear motion. A drag link is a forged rod that connects the Pitman arm to the steering control arm. The drag link can be a one- or two-piece component. The length of two-piece design is adjustable, which makes it easy to center the steering gear with the wheels straight ahead. The drag link is connected at each end by ball joints. These ball joints help isolate the steering gear and Pitman arm from axle motion. The steering control arm connects the drag link to the steering knuckle on the driver side of the vehicle. When the drag link is moved in a linear direction, the steering control arm moves the steering knuckle, which changes the angle of the steering knuckle spindle. Steering knuckles mount to the rigid front axle beam by means of steel pins known as kingpins. They provide the ability for the pivoting action required to steer the vehicle. The steering knuckle incorporates the spindle onto which wheel bearings and wheel hubs are mounted, plus a flange to which the brake spider is bolted. A steering control arm is attached to the upper portion of the left side steering knuckle and tie-rod arms are attached to both left and right steering knuckles. Tie-rod arm is the means used to transfer and synchronize steering action on both steer wheels on a steering axle. The steering arm or lever controls the movement of the driver side steering knuckle because it connects directly to it. The steering knuckles are required to be connected to each other so that they act in unison to steer the vehicle. Transferring this steering motion to the passenger side steering knuckle is achieved by using a tie-rod or cross tube assembly. Axle beam steering system consists of a steering wheel, which imparts motion to the steering box. This conveys the steering effort through the Pitman arm and drag link directly to one of the two stub axles pivoting at the ends of the axle beam. A track rod joins both the stub axles together. The steering box provides a gear reduction so that, with only a small effort, a much larger force can be applied to the steering linkage. At the same time, the degree of stub axle movement will be reduced for a given angular movement of the steering wheel. This is desirable as it prevents the steering being oversensitive to the drivers touch on the wheel. With the rigid beam suspension, a stub axle is pivoted at each end of the axle beam so that relative movement can take place only in the horizontal plane. Therefore, the effective track rod length is not influenced by any vertical suspension deflection. The cab and the chassis of HXXX are $2.5 \mathrm{~m}$ width $\times 3.9 \mathrm{~m}$ height $\times 2.3 \mathrm{~m}$ length.

The vibration phenomena generated in a vehicle steering system can be classified as forced vibrations such as flutter and kickback and self-excited vibrations such as shimmy. Flutter is a stationary vibration generated by a periodic external force due to an unbalanced front wheel, etc., while kickback is transient vibration generated by an external force due to unevenness of the road, etc. Shimmy, on the other hand, is vibration generated by dynamic characteristics of the tire, etc. In the process of HXXX development, excessive vibration of the steering wheel for idle conditions was identified during subjective evaluation phase drives. There are many factors that may cause vibration at idle, including vibrational excitation sources, such as the engine and engine mounts, and the transmission channels, such as the body structure, suspension and steering wheel itself. Thus, identifying the source of the vibration is a very complex problem. Therefore, a procedure was applied to identify this vibration phenomenon and to explore alternatives to decrease or eliminate it. To identify the problem, a series of tests was performed.

\section{EXPERIMENTAL MODAL ANALYSIS (EMA) OF THE HXXX STEERING WHEEL}

To obtain the modal parameters of the steering wheel and steering column, two modal tests were performed on HXXX with an impact hammer. The first test was performed on the steering wheel as mounted to the cab, and the second test was performed on the steering wheel as detached from the cab (free-free conditions). The aim of performing modal analysis on the steering wheel free-free conditions was to use the test results to correlate the CAE model of the steering wheel. The modal analysis measurements were taken using a Siemens LMS SCADAS multichannel analyzer system. Four Brüel \& Kjær model 4506B Triaxial (100 mV/g sensitivity) accelerometers, two different sized PCB Piezotronics impulse force hammers with soft plastic brown tip $(0.23 \mathrm{mV} / \mathrm{N}$ sensitivity), a Siemens LMS Test Lab 13A SL1 for data acquisition and processor software were used for the modal impact testing. The prototype vehicle was updated with the latest level parts. An old L-shaped bracket was removed, and the proposed steering column cross-car beam connection reinforcements were attached before the test. Two hammers were used in the tests since the hammer used for the detached steering wheel test (referred to as hammer \#2 hereafter) was not sufficient to excite the accelerometers that were placed on the steering column and mounting bracket while performing the test when the steering wheel was attached to the vehicle. The measurements for the modal analysis were performed using an LMS multianalyzer system. LMS Test Lab Structures, a dedicated application software package, was used for the measurements and data validation. LMS Test Lab Structures Impact Testing and Modal Analysis modules were used to support the generation and import of geometry, definition of measurement sequences on the various points and directions (DOFs), and subsequent transfer/export of DOF-labeled measurement data.

Eight accelerometer holders were placed on the steering wheel, and two accelerometer holders were placed on the steering column on mounting clips that were fastened to the measurement locations with glue. Since there were four accelerometers, the test was completed in three turns. Measurements taken from points 1, 2, 3, 4 firstly, then the accelerometers were removed and mounted to points 5, 6, 7 and 8 in the second turn, and same process as repeated for points 9 and 10 .

The aim of the measurements was to determine the lower modes considering idle frequency; thus, the $0-160 \mathrm{~Hz}$ frequency range was of interest (a frequency range of $0-320 \mathrm{~Hz}$ was set in the LMS software to obtain reliable results in the frequency range of interest and avoid damping effects on the results). The accelerometers on the steering wheel were positioned at twelve o'clock (top of the wheel), the spoke and wheel intersections, the points between the spokes and the top of the wheel (one at ten o'clock and one at two o'clock) and 


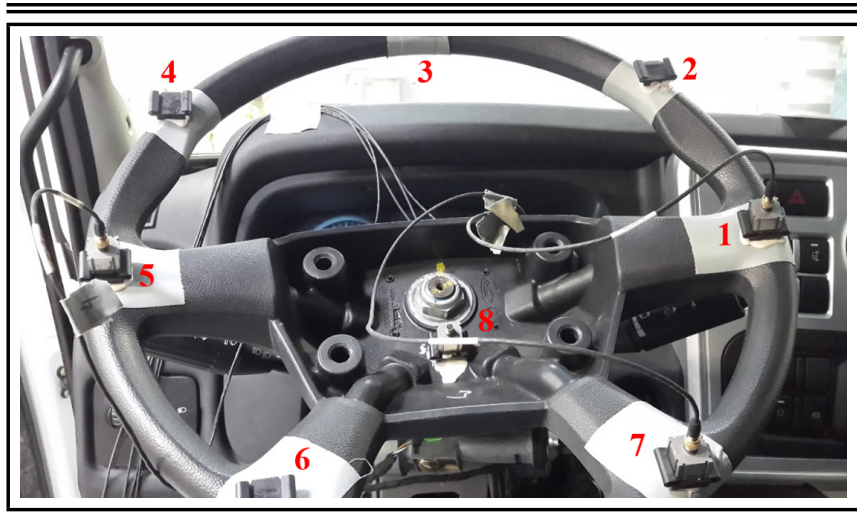

Figure 2. Accelerometer locations on the steering wheel.

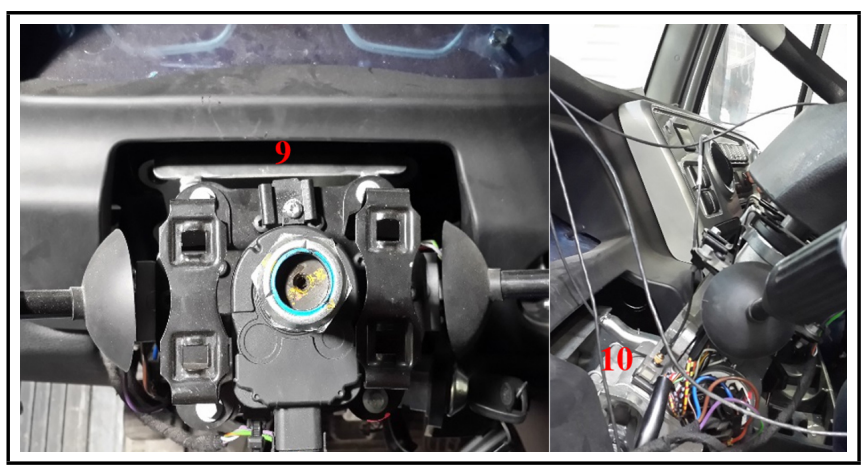

Figure 3. Accelerometers \#9 and \#10 located on the steering column.

the center of the hub. Two accelerometers were placed on the steering column. The accelerometer locations are shown in Figs. 2-4.

An impact was applied to the steering wheel rim 3 o'clock position, point 1 , and measurements were taken from points 1 to 10 . The impact was applied perpendicular (in the direction of Z) and horizontal (in the direction of $\mathrm{Y}$ ) to the steering wheel rim, as shown in Fig. $4 a$ and $4 b$, respectively. Since there were 4 accelerometers, measurements were taken from points $1,2,3$, and 4 first; then, the accelerometers were removed and mounted to points 5, 6, 7 and 8 for the second turn, and the same process was repeated for points 9 and 10. The steering wheel was detached from the test vehicle, tied to a flexible line and suspended to isolate the test object from the environment and achieve free-free boundary conditions, as shown in Fig. 5. The main objective in performing the steering wheel free-free test was to use the test results for correlation with the steering wheel FE model.

A force was applied to Point 1 (the 3 o'clock position) with

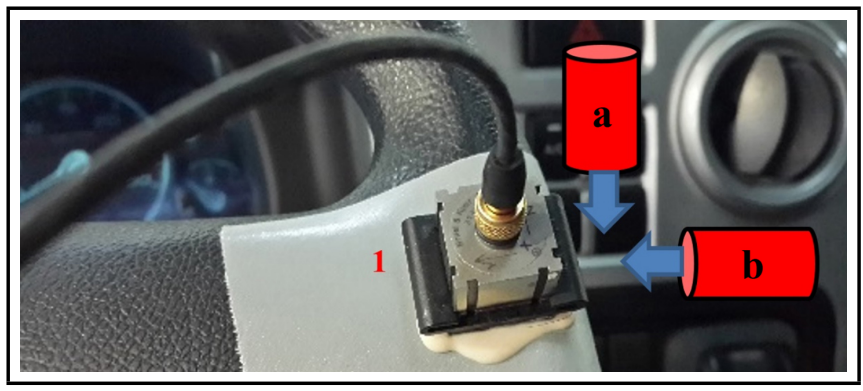

Figure 4. Accelerometer positioning on the steering wheel, Point 1 (excitation point).

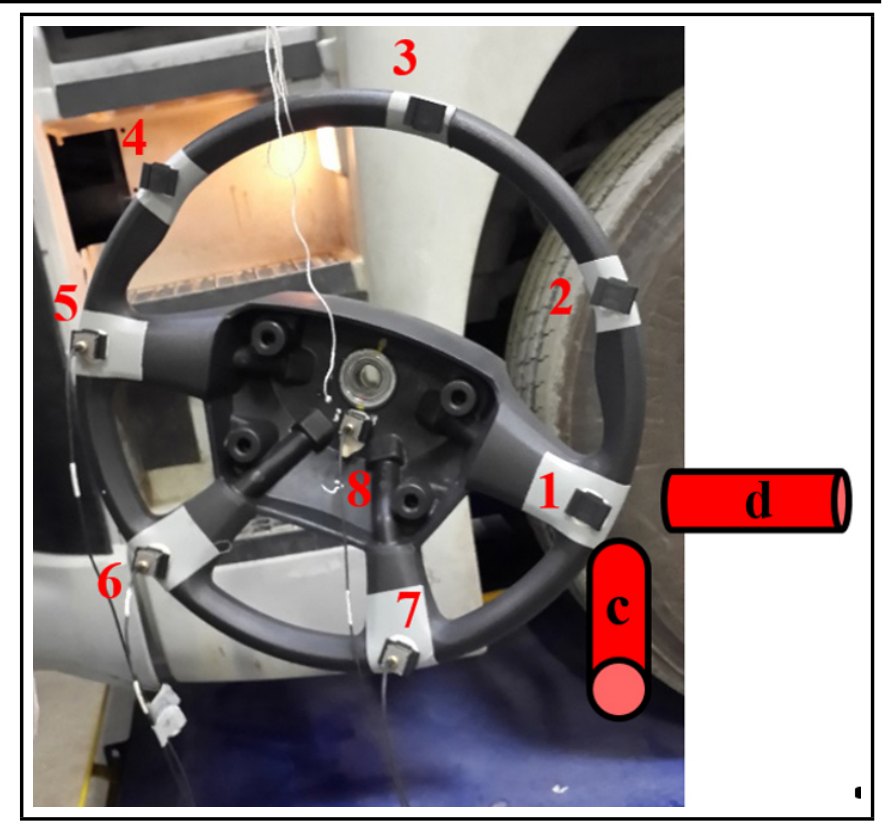

Figure 5. Impact and measurement points on the steering wheel.

the smaller impact hammer to excite the steering wheel. Forces were applied to the $-\mathrm{X}$ and $+\mathrm{Y}$ directions. There were eight measurement points on the steering wheel: 1 accelerometer on the top of the rim (12 o'clock), 4 accelerometers on the spoke and rim intersections, 2 accelerometers on the unsupported section of the rim that is between the top of the rim and the spokes (approximately 3 o'clock and 10 o'clock) and 1 accelerometer just below the wheel hub. Frequency responses in the range of $0-320 \mathrm{~Hz}$ were of interest; thus, a frequency range of $0-640 \mathrm{~Hz}$ was set in the LMS software to avoid damping effects on the frequency responses.

The accuracies of the results were checked by tracking the resultant diagrams (Fig. 6), mainly the coherence diagram, during the test after each measurement.

Checking the diagrams obtained from the measurements ensured the following:

- The frequency response functions have peaks at the frequencies corresponding to the natural frequencies of the test objects.

- Between two natural frequencies (peaks), there is an antiresonance point that appears as an inverse peak in the diagram.

- In the coherence diagram, there are breakdowns that correspond to antiresonance regions.

- For all the regions except the antiresonance regions, the coherence function is equal to 1 .

The natural frequencies and modal shapes of the steering wheel and column were obtained from the frequency response function stabilization diagrams. The first three modes of the steering wheel are given in Table 1.

\section{FE MODAL ANALYSIS OF THE HXXX STEERING WHEEL AND COLUMN}

For dynamic structural analysis, the FE model of the cab of HXXX with all the components was used. A threedimensional model of the cab and steering system was built 


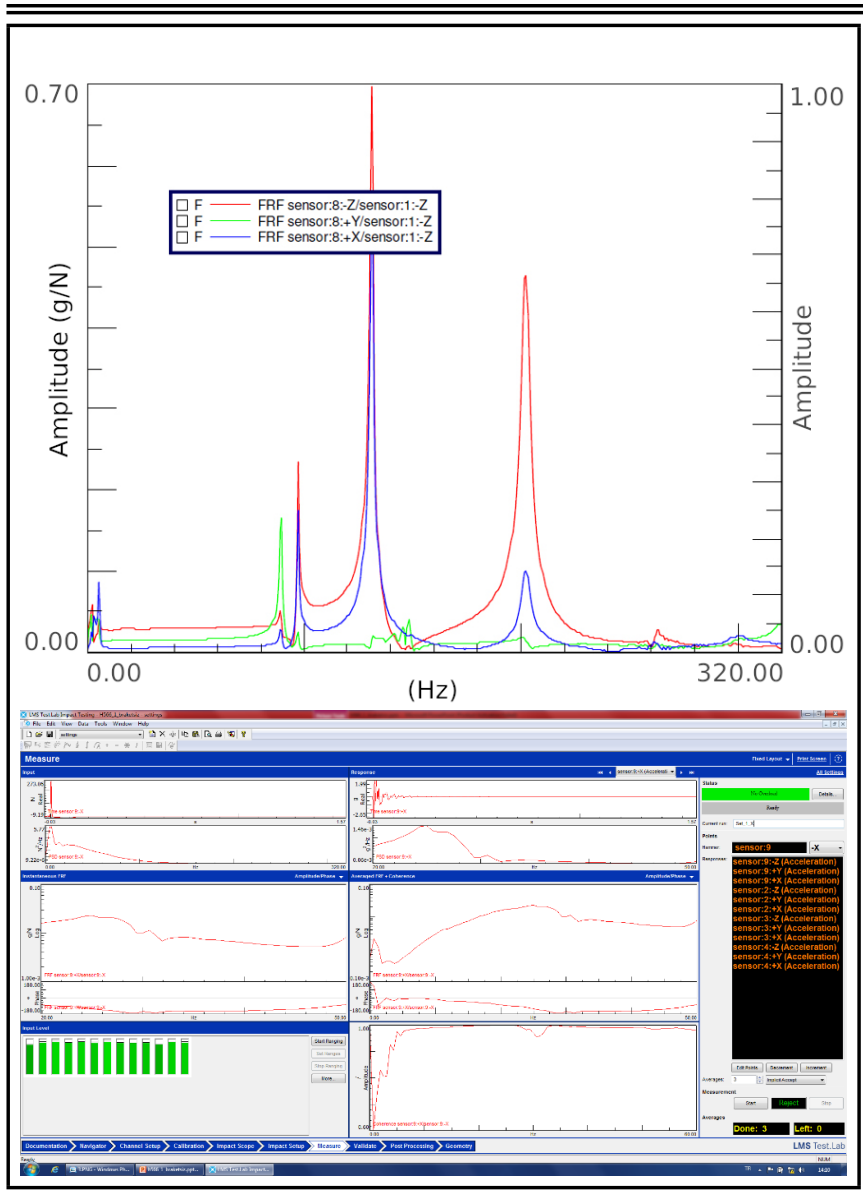

Figure 6. Frequency response function (accelerance) and coherence function diagram.

Table 1. Steering wheel modes.

\begin{tabular}{|l|l|l|}
\hline & On Vehicle & Free - Free \\
\hline 1st mode & $27.9 \mathrm{~Hz}$ & $96.3 \mathrm{~Hz}$ \\
\hline 2nd mode & $29.4 \mathrm{~Hz}$ & $126.5 \mathrm{~Hz}$ \\
\hline 3rd mode & $31.6 \mathrm{~Hz}$ & $150.2 \mathrm{~Hz}$ \\
\hline
\end{tabular}

using CATIA V5 software, exported in STP format, and imported into ANSA software as shown in Fig. 7. ANSA and $\mu \mathrm{ETA}$, the pre- and postprocessing packages of BETA CAE Systems, were used for modeling and postprocessing, respectively. Before building the FE model, the free surface of the model was checked to ensure that all the surfaces were closed. FEA was performed using NASTRAN.

The CAE model of the trimmed body was generated in ANSA. The trimmed body structure represented a vehicle without the chassis (frame, suspension, brakes) and powertrain subsystems. When all the closures (door, hood, and decklid) and other subsystems (steering column and seats) and trim items (carpeting, etc.) were removed from the trimmed body, the resulting structure is called the "body-in-prime" (BIP, or "body-in-white" with glass). An FE trimmed body model was created by "trimming up" a BIP model with system models such as closures, seats, instrumental panel (IP) assembly (including the steering column, steering wheel, and cross-car beam), bolted-on subframes, and nonstructural trim items (heater module, carpets, etc.). The BIP and trimmed body played an important role in determining the dynamic characteristics of the vehicle. The trimmed body FEM model consisted of 1311966 shell elements in total (959924 quads,

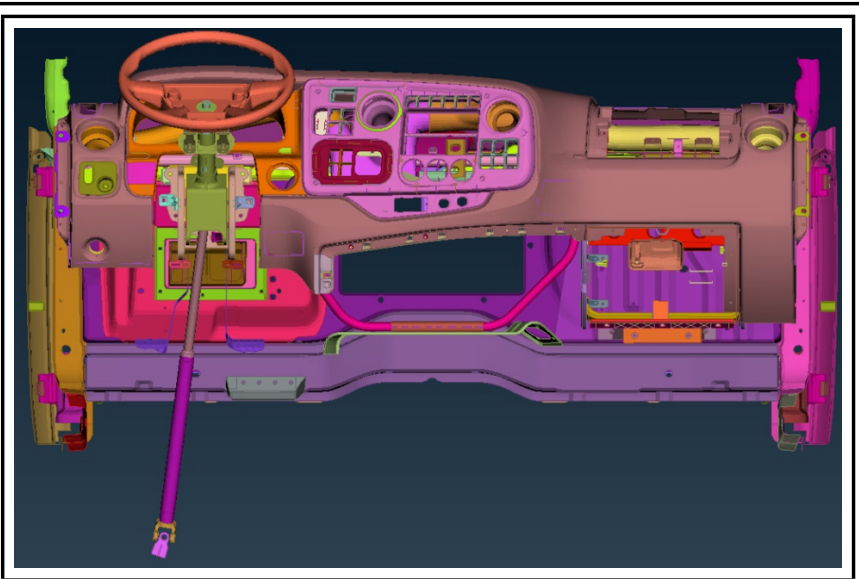

Figure 7. Full CAE model.

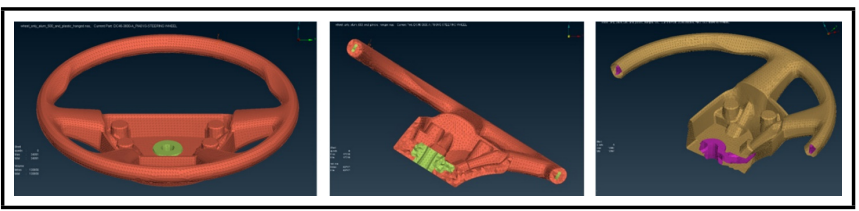

Figure 8. Steering wheel FE model.

352042 trias) and 1272711 volume elements in total (1233609 tetras, 1674 pentas and 37428 hexas). The meshing parameters and quality criteria were imported into ANSA to ensure that the generated mesh fulfilled the prescribed quality criteria. The steering wheel assembly consisted of an armature and rim, urethane cover, airbag bracket, airbag, spoke cover and stub shaft. The stub shaft and air bag bracket were not included in the model since the steering wheel tested had no stub shaft or air bag bracket during testing. The HXXX steering wheel FE model consists of 34891 shells and 130656 solid elements, as shown in Fig. 8.

The armature was modeled with a rim (as on casting parts) and a polyurethane covering of the rim and spokes, and the armature was modeled with 3D CTETRA elements with an average element size of $3,0 \mathrm{~mm}$. On the top of the solid mesh, 2D CTRIA3 shell elements with a thickness of $0.05 \mathrm{~mm}$ were used. Common grids between the steering wheel and wrapping foams and RBE2 for rigid connections such as bolts or screws were used. Important features such as beads and ribs and all holes with diameters equal to or greater than $5 \mathrm{~mm}$ were included in the model. The model quality is considered acceptable when it meets the general FE mesh quality requirements.

The steering wheel assembly was constrained by hanging from the rim by a single point constraint to restrict the $\mathrm{z}$ translation direction from the same point (1 o'clock) from which the steering wheel was hung during modal testing.

Aluminum material properties were assigned to the armature. Polyurethane material properties were assigned to the rim and hub cover. The total mass of the steering wheel assembly was $3.4 \mathrm{~kg}$, the exact weight of the steering wheel measured during the test.

FEA was performed initially on the trimmed body to obtain the steering wheel and column modes. Several modifications and improvements were performed on the model, such as the deletion of the L-shaped brackets and the addition of two rein- 


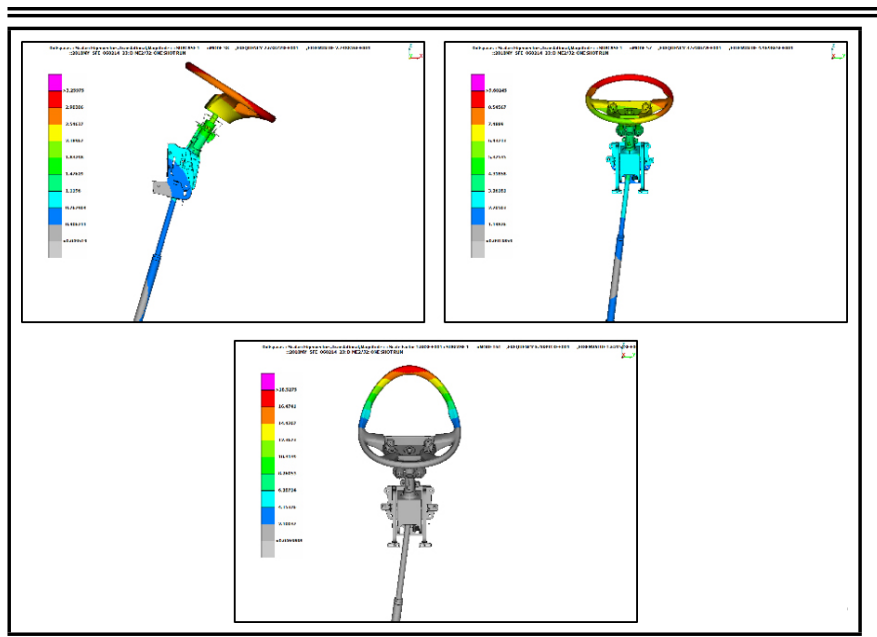

Figure 9. Mode shapes of the steering wheel and column.

forcement brackets instead, the addition of the steering lower shaft model and steering wheel model modification to obtain better correlation with the EMA. Additionally, FEA was performed on only the steering wheel before and after the steering wheel model improvements. Improvements were made in the steering wheel model with the help of the modal test results performed on the steering wheel assembly in free-free conditions. Iterations were continued until the modal frequencies of the steering wheel converged to the test results. Additionally, FEA was performed again with several iterations, such as the addition of bolts that were proposed to improve the steering wheel vibration.

The trimmed body FE model was submitted to the supercomputer, and FEA was performed in NASTRAN by applying free-free boundary conditions. Bolts were removed from the trimmed body model for the first analysis. A second analysis was performed with the bolts added to the model to estimate the change in the modal behavior of the steering system with the proposed bolts that restrict z-movement of the steering column assembly. The output file was processed through MetaPost. There were seven rigid body modes; the first six modes were rigid body modes of the steering wheel, and the seventh mode was rotation of the steering column about its local axis. For the trimmed body, there was an additional steering wheel nimble mode that was very close to $0 \mathrm{~Hz}$ (usually approximately $0.2 \mathrm{~Hz}$ ). Additional rigid body modes were usually an indication of unconnected or misconnected parts.

To obtain the steering wheel and column modes, measurement nodes were defined on the display model. Nodes around the region where measurements were taken during the modal test on the steering wheel and column were chosen on the model, and the response frequencies were collected.

According to the FEA results, the first mode (vertical column mode) is correlated with the test results. However, the correlation between the FEA and the test results was lower with the following modes. The FE model of the trimmed body consists of a great number of parts, material assumptions, shell modeling of thin parts, shell thickness estimations and contact point assumptions, and these factors can contribute to divergent results. All the assumptions that were made for the material properties, shell thickness values, and contact points must be rechecked and updated if required. Compared with the

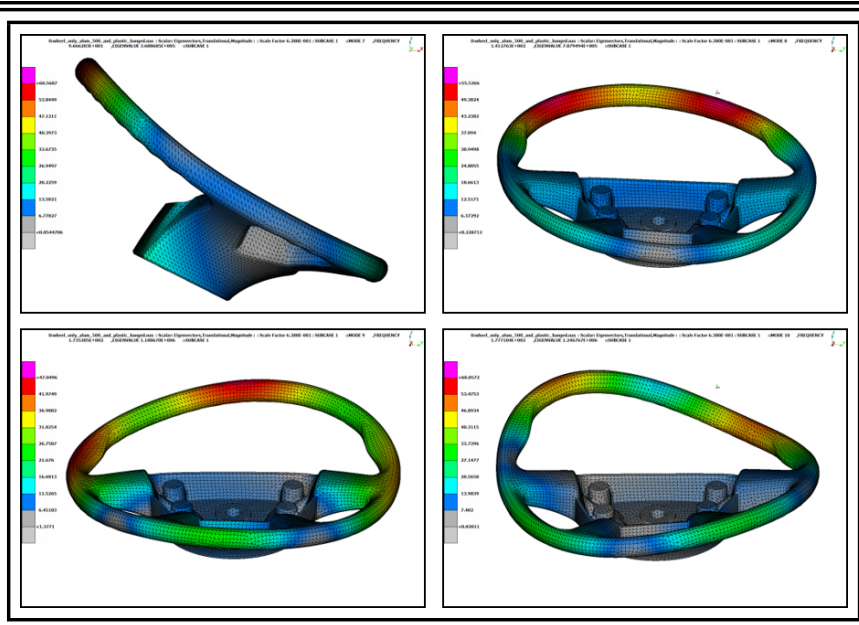

Figure 10. Mode shapes of the steering wheel.

Table 2. Comparison of experimental and FE modal analyses.

\begin{tabular}{|l|l|l|l||}
\hline $\begin{array}{l}\text { Steering Wheel } \\
\text { Free - Free }\end{array}$ & EMA & FEA & $\begin{array}{l}\text { Discrepancy (\%) } \\
\text { (FEA - EMA)/EMA }\end{array}$ \\
\hline 1st Mode & $96.3 \mathrm{~Hz}$ & $96.6 \mathrm{~Hz}$ & 0.31 \\
\hline 2nd Mode & $126.5 \mathrm{~Hz}$ & $141.3 \mathrm{~Hz}$ & 11.70 \\
\hline 3rd Mode & $150.2 \mathrm{~Hz}$ & $173.5 \mathrm{~Hz}$ & 15.51 \\
\hline \hline Steering Wheel & EMA & FEA & $\begin{array}{l}\text { Discrepancy (\%) } \\
\text { and Column }\end{array}$ \\
\hline 1st Mode & $25.5 \mathrm{~Hz}$ & $26.5 \mathrm{~Hz}$ & 3.92 \\
\hline 2nd Mode & $27.8 \mathrm{~Hz}$ & $35.5 \mathrm{~Hz}$ & 27.70 \\
\hline 3rd Mode & $53.6 \mathrm{~Hz}$ & $64.0 \mathrm{~Hz}$ & 19.40 \\
\hline
\end{tabular}

results before the steering column and reinforcement bracket change, the vertical column mode is higher with the introduced bolts and brackets. The first mode of the steering column is still very close to the engine idle firing frequency. The first mode (vertical column mode) must be increased to achieve the target setting $(35 \mathrm{~Hz})$.

Normal mode analysis of the steering wheel assembly was performed in NASTRAN from 0 to $320 \mathrm{~Hz}$ with the DOF 123456 unconstrained (free-free boundary conditions). The first six modes were the steering wheel rigid body modes. The modal frequencies of the steering wheel assembly were obtained from the frequency - mode chart given in Table 2. The mode shapes are shown in Figs. 9 and 10.

The FE model of the steering wheel was improved before the analysis since the analysis results before the model modification were not correlated with the test results. The rim and hub cover models were added to the previous model.

\section{CONCLUSIONS}

In this study, EMA and FEA are performed on the steering wheel and column of HXXX. According to the FEA results performed on the free-free steering wheel, the first mode of the steering wheel is highly correlated with the test results. Correlation between the experimental and FEA results is achieved by steering wheel CAE model improvements. The second and third modes of the steering wheel are still not correlated with the EMA results. Although there are few geometric simplifica- 
tions applied to the CAE model, the material property assumptions (especially considering that the exact material properties of the steering wheel rim are unknown), the shell meshing of thin components, the estimation of shell thicknesses and the contact point assumptions may have led to uncorrelated results.

According to the EMA results, the vertical mode of the steering column was $27.8 \mathrm{~Hz}$, which is still very close to the engine idle firing order frequency. Before the column modification, the vertical mode of the steering column is $23.4 \mathrm{~Hz}$. An increase in $4.4 \mathrm{~Hz}$ is achieved, but the target is above $35 \mathrm{~Hz}$, so design optimization must be performed on the proposed brackets. The steering column holder bracket must be extended as much as possible in the vertical axis to increase the first mode of the steering column to restrict the vertical motion.

The implementation of the proposed bolts is verified by testing and FEA. The experiments and analysis were performed with and without the bolts. Comparisons of the measured and predicted results indicated that the bolts increased the steering column vertical mode by approximately $2.4 \mathrm{~Hz}$.

\section{REFERENCES}

1 Szczotka, M. Simulation and optimisation of the steering kickback performance, J. Theor. Appl. Mech., 49 (1), 187208, (2011).

2 Kim, B. K., Grenier, G. C., and Cerrato-Jay, G. A Numerical and Experimental Study on Power Steering Shudder, SAE Technical Paper 2008-01-0501, (2008). https://dx.doi.org/10.4271/2008-01-0501

3 Mangun, D. Simulation and characterization of tire nonuniformity-induced steering nibble vibrations through integrated subsystems modeling, South Carolina, Master of Science, Graduate School of Clemson University, (2006).

4 Sugiyama, A., Kurishige, M., Hamada, H., and Kifuku, T. An EPS Control Strategy to Reduce Steering Vibration Associated with Disturbance from Road Wheels, SAE Technical Paper 2006-01-1178, (2006). https://dx.doi.org/10.4271/2006-01-1178

5 Zhang, L., Ning, G., and Yu, Z. , Brake Judder Induced Steering Wheel Vibration: Experiment, Simulation and Analysis, SAE Technical Paper 2007-01-3966 (2007). https://dx.doi.org/10.4271/2007-01-3966

6 Matsunaga, T., Tanaka, T., and Nishimura, S., Analysis of Self-Excited Vibration in Hydraulic Power Steering System: Prevention Against Vibration by Supply Line, SAE Technical Paper 2001-01-0488 (2001). https://dx.doi.org/10.4271/2001-01-0488

7 Wang, S., Shi, W., Wu, G., and Nie, S., Research and Improvement of Steering Wheel's Idle Shaking, SAE Technical Paper 2013-01-1711 (2013). https://dx.doi.org/10.4271/2013-01-1711

8 Demers, M. A. Steering Wheel Vibration Diagnosis, SAE Technical Paper 2001-01-1607, (2001). https://dx.doi.org/10.4271/2001-01-1607
9 Kim, J. H., Jung, S. G., and Kim, K. S. An Investigation of the Steering Wheel Vibration and its Reduction in Passenger Cars, SAE Technical Paper 852267, (1985).

10 Kim, K. C., Choi, I. H., and Kim, C. M. , A Study on the Advanced Technology Analysis Process of Steering System for Idle Performance, SAE Technical Paper 2007-01-2339 (2007). https://dx.doi.org/10.4271/2007-01-2339

11 Botti, J., Venizelos, G., and Benkaza, N. Optimization of Power Steering Systems Vibration Reduction in Passenger Cars, SAE Technical Paper 951253, (1995). https://dx.doi.org/10.4271/951253

$12 \mathrm{Su}, \mathrm{L}$., Zhou, H., and Zhu, L. S. The optimization of a middle-sized passenger car steering wheel vibration at idle speed, Adv. Mater. Res., 291, 1937-1940, (2011). https://dx.doi.org/10.4028/www.scientific.net/AMR.291294.1937

13 Slave, R. B., Vianna, E. P., Perseguim, O. T., Andrade, F., Fonseca, F., Felício, J. A., Spada, J. N., Comparini, F., Berti, O., and Zambon, H., Vibration Mode Study of Steering Columns for Commercial Vehicles, SAE Technical Paper 2008-36-0193 (2008). https://dx.doi.org/10.4271/200836-0193

14 Chen, S. M., Wang, D. F., Tan, G. P., and Zan, J. M. Modal analysis of automotive steering system based on finite element method, Appl. Mech. Mater., 121-126, 2085-2090, (2011). https://dx.doi.org/10.4028/www.scientific.net/AMM.121126.2085

15 Guo, L. X., Ji, G. H., Zhao, L. P., and Li, J. L. Static and dynamic finite element analysis on the steering system of automobiles, Appl. Mech. Mater., 121-126, 3498-3501, (2011). https://dx.doi.org/10.4028/www.scientific.net/AMM.121126.3498

16 Gao, X., and Wang, Y. X. Modal analysis of electronic power steering based on finite element method, Adv. Mater. Res., 452-453, 354-358, (2012). https://dx.doi.org/10.4028/www.scientific.net/AMR.452453.354

17 Bianchini, E. Active Vibration Control of Automotive Steering Wheels, SAE Technical Paper 2005-01-2546, (2005). https://dx.doi.org/10.4271/2005-01-2546

18 Landreau, T., and Gillet, V. Analysis and control of vehicle steering wheel angular vibrations, ADAMS User's Conference, Spain, (1999).

19 Zhang, L., and Dong, E. Dynamics simulation on vehicle steering mechanism, Proceedings of the 2nd International Conference on Electronic and Mechanical Engineering and Information Technology (EMEIT-2012), Curran, Amsterdam, (2012). https://dx.doi.org/10.2991/emeit.2012.432 
20 Othman, W. Experimental study of steering wheel vibration in dynamic condition (Bachelor of Mechanical Engineering (Automotive)), Malaysia, Universiti Teknikal Malaysia Melaka, (2011). https://dx.doi.org/10.4271/1999-01-0393

21 Shim, Y. J., and Shin, C. S. The Study for the Reduction of Idle Vibration of Steering System Through the Use of a Weight Reduction Method, SAE Technical Paper 1999-010393, (1999). https://dx.doi.org/10.4271/1999-01-0393

22 Kim, J. H., and Choi, S. P. An Application of a Dual Mode Dynamic Damper to Control Steering Wheel Shimmy and Shake Problems, SAE Technical Paper 871153, (1987).

23 Abreu, R. D. A., and Moura, F. Operational Modal Analysis Techniques used for Global Modes Identification of Vehicle Body Excited from a Vehicle in Idle Engine, SAE Technical Paper 2012-36-0639, (2012). https://dx.doi.org/10.4271/2012-36-0639

24 Britto, V. A. J., Loganathan, E., Sadasivam, S., Hatti, K., and Sankaranarayana, S. Methodology of Steering Assembly Development for NVH for Medium and Heavy Commercial Vehicle, SAE Technical Paper 2013-01-2351, (2013). https://dx.doi.org/10.4271/2013-01-2351

25 Fujiwara, Y., and Nakayasu, M. Analysis of Vibrational Modes of Vehicle Steering Mechanisms, SAE Technical Paper 710627, (1971).

26 Sugita, H., and Asai, M. Experimental Analysis for the Steering Wheel Vibration Using Mechanical Impedance Methods, SAE Technical Paper 870971, (1987).

27 Shi, W., Wu, G., Wang, S., and Chen, Z. Improvements of steering wheel's idle shaking, Proceedings of the FISITA 2012 World Automotive Congress. Lecture Notes in Electrical Engineering, Berlin, Heidelberg, (2013). https://dx.doi.org/10.1007/978-3-642-33832-8_30

28 Xie, R., Liu, Z., Long, S., and Tian, Z. Test and simulation integrated transfer path analysis and optimization of the steering wheel vibration in idle, Proceedings of the FISITA 2012 World Automotive Congress. Lecture Notes in Electrical Engineering, Berlin, Heidelberg, (2013). https://dx.doi.org/10.1007/978-3-642-33832-8_32

29 Giacomin, J., Shayaa, M., Dormegnie, E., and Richard, L. Frequency weighting for the evaluation of steering wheel rotational vibration, Int. J. Ind. Ergon., 33 (6), 527-541, (2004). https://dx.doi.org/10.1016/j.ergon.2003.12.005

30 Ereke, İ. M. Katı ön aksta yol pürüzlülü̈̆̈̈̈nün direksiyon sarsintısina etkisi, Istanbul, Istanbul Teknik Universitesi Fen Bilimleri Enstitüsü, (1986).

31 Jeon, B. H. Proposed automobile steering wheel test method for vibration. PhD Thesis, Brunel, School of Engineering and Design Brunel University, (2010).
32 He, S., Chen, B., Jiang, Z., Wang, Y., and Liu, F. Control of steering wheel idle jitter based on optimization of engine suspension system with verifications using multi-sensor measurement, Int. J. Distrib. Sens. Netw., 14 (6), 1550147718782373, (2018). https://dx.doi.org/10.1177/1550147718782373

33 He, S., Tang, T., Xu, E., Ye, M., and Zheng, W. Vibration control analysis of vehicle steering system based on combination of finite-element analysis and modal testing, J. Vib. Control, 26 (1-2), 88-101, (2020). https://dx.doi.org/10.1177/1077546319876798

34 Peng, J. S. Multi-objective optimization of vibration characteristics of steering systems based on GA-BP neural networks, J. Vibroengineering, 19 (5), 3216-3229, (2017). https://dx.doi.org/10.21595/jve.2017.18107

35 He, S., Tang, T., Ye, M., Xu, E., and Jiang, Z. A multi-point iterative analysis method for vibration control of a steering wheel at idle speed, IEEE Access, 7, 88399-88417, (2019). https://dx.doi.org/10.21595/jve.2017.18107

36 Sangeeta, G. M., Patil, G. P., and Kharche, N. A. Design optimization of steering rod and performance of structural analysis, Int. J. Eng. Res. Technol., 3 (6), 21382143, (2014).

37 Pattathil, A., Soherwardi, O., and Iqbal, S. A Mitigation Strategy for Steering Wobble Phenomenon in Passenger Vehicle, SAE Technical Paper 2019-26-0183, (2019). https://dx.doi.org/10.4271/2019-26-0183

38 Sendur, P., Kurtdere, A., Akaylar, O., and Otosan, F. A methodology to improve steering wheel vibration of a heavy commercial truck, USA, Institute of Noise Control Engineering, (2016).

39 Fridman, L., Brown, D. E., Angell, W., Abdić, I., Reimer, B., and Noh, H. Y. Automated synchronization of driving data using vibration and steering events, Pattern Recognit. Lett., 75, 9-15, (2016). https://dx.doi.org/10.1016/j.patrec.2016.02.011

40 Prashanth, G., Kumar, P. P., and Reddy, M. D. Mathematical modeling of vibration in steering wheel assembly of commerical vehicles, Int. J. Eng. Res. Technol., 4 (4), 837841, (2015).

41 Reddy, N. M. Study of vibrations on steering wheel - a review, J. Chem. Pharm. Sci.

42 Shelke, P., and Dhale, A. Experimental analysis for the vibration reduction of steering wheel assembly of agricultural tractor, Proceedings 2019: Conference on Technologies for Future Cities (CTFC), (2018).

43 Velmurgan, M., Srikanth, M. V., and Balakrishna, K. Vibration analysis on car steering due to smooth and rough road condition, Int. J. Trend Sci. Res. Dev., 1 (6), 32-37, (2017).

44 Ye, S., Hou, L., Zhang, P., Bu, X., Xiang, J., Tang, H., and Lin, J. Transfer path analysis and its application in low-frequency vibration reduction of steering wheel of a passenger vehicle, Appl. Acoust., 157, 107021, (2020). https://dx.doi.org/10.1016/j.apacoust.2019.107021 